\title{
The secret of sleep...
}

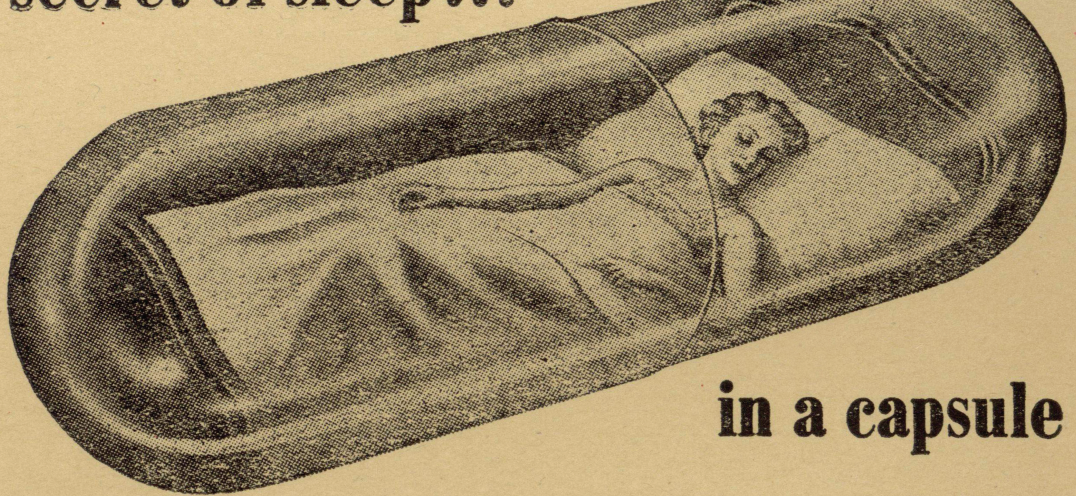

\section{Dilly BARBITURATES}

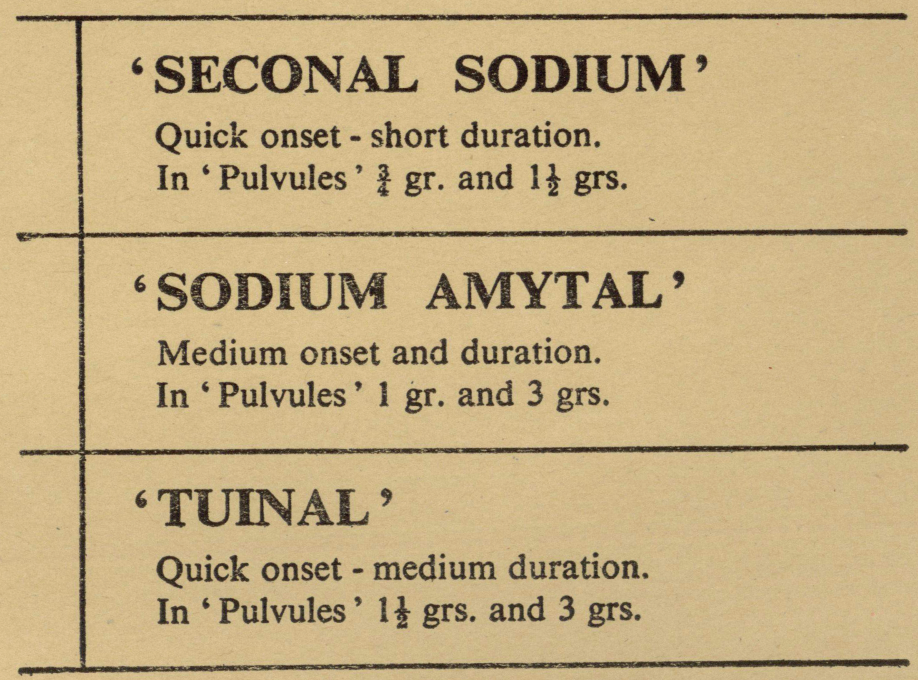

ELI LILLY \& COMPANY LIMITED, BASINGSTOKE, ENGLAND 


\section{JOURNAL OF MENTAL SCIENCE}

\section{CONTENTS FOR APRIL, 1956}

\section{Original Articles-}

PAGB

The Contribution of the Physical Sciences to Psychological Medicine; by John Dunne, M.D., D.M.D., D.P.H. .

The Thirtieth Maudsley Lecture: Perception and Imperception; by Sir W. Russell Brain, Bt., D.M., LL.D., D.C.L., P.R.C.P.

"Memory Function" in Psychiatric Patients Over Sixty, Some Methodological and Diagnostic Implications; by M. B. Shapiro, M.A., Ph.D., F. Post, M.B., M.R.C.P., D.P.M., B. Löfving, F.K.(Stockholm), and J. Inglis, M.A., Dip.Psych.

A Review of the Psychotic Elderly Resident in a Mental Hospital; by G. I. Tewfik, M.D., D.P.M.

Clinical Applications of EEG in Psychiatry; by Denis Hill, M.B., F.R.C.P., D.P.M.

Research Prospects in the Psychology of Ageing; by Dennis B. Bromley, B.A.

A Re-evaluation of the Fugue; by W. P. Berrington, M.D., D.P.M., D. W. Liddell, M.B., M.R.C.P., D.P.M., and G. A. Foulds, M.A., Ph.D.

Encephalitis Periaxialis Diffusa with Survival for Thirty-six Years; by $R$. $M$. Stewart, M.D., F.R.C.P., D.P.M.

Spatial Disorientation in Senile Dementia; by Moyra Williams, D.Phil.

Friederich C. G. Scheidemantel: The First Systematic Text in Psychosomatic

Medicine (1787); by Ernest Harms, M.D. . . . • . . .

The Psychoses of Adolescence; by The late Dalton E. Sands, F.R.C.P.Ed., D.P.M. .

Colour-form Response as a Function of Mental Disorder; by J. D. Keehn and Aimee Sabbagh

Some Aspects of the Ganser State; by Milo Tyndel, M.D., Ph.D.(Vienna)

The Cephalic Post-traumatic Syndrome. Pathological Observations; by Adams A. McConnell, M.A., M.Ch., F.R.C.S.I. .

A Logical and Cultural Analysis of Hallucinatory Sense-experience; by $J$. $R$. Smythies, M.A., M.D., M.Sc., D.P.M.

Cerebral Cysticercosis with Mental Symptoms; by J. M. Sutherland, M.D., M.R.C.P.E., and J. M. Rosie, M.D., D.P.M.

The Neuropsychiatric Aspects of Familial Dysautonomia (The Riley-Day Syndrome); by William Forster, M.B., B.S., D.P.M., and Milo Tyndel, M.D., Ph.D.(Vienna)

Mental Illness and Social Conditions in Bristol; by E. H. Hare, M.D., D.P.M. $\quad$. 349

The Treatment of Depression with Methylamphetamine; by G. de M. Rudolf, M.R.C.P., D.P.M., D.P.H.

Reviews

Bibliography and Epitome 